\title{
Strategies for Managing Information Flow in Nigeria Healthcare System
}

\author{
Ojerinde Oluwaseun \\ Federal University of Technology, \\ Minna, Niger State, \\ Nigeria
}

\author{
Iroju Olaronke \\ Adeyemi College of Education, \\ Ondo, Ondo State, \\ Nigeria
}

\begin{abstract}
The healthcare system is an information intensive domain that is responsible for capturing, processing and storing large volumes of health information which could be clinical, research or administrative in nature. Healthcare information is primarily used for making decisions, improving the efficiency and quality of healthcare systems as well as conducting research to enhance medical science in both developed and developing countries. Healthcare information is usually stored in paper form, physical files or digital formats. However, developing countries such as Nigeria are faced with the challenge of moving from paper based health information system towards the digital formats that facilitates an integrated computerized health information system. Nevertheless, healthcare information is usually transmitted among disparate healthcare providers within or across different healthcare institutions. However, healthcare entities in developing countries are plagued with the difficulty of how to successfully and effectively manage information as it flows across the continuum of care. Consequently, this results in inappropriate decision making, ineffective planning, increase in medical errors and cost as well as a decline in the quality of patients' care. Based on this background, this paper appraises how information flows within and across diverse healthcare organizations in developing countries with a particular reference to Nigeria. The paper also recommends ways of managing information flow within the Nigeria healthcare system.
\end{abstract}

\section{General Terms}

Information, healthcare system, interoperability

\section{Keywords}

Information flow, information flow management, healthcare, Nigeria

\section{INTRODUCTION}

Information is very vital for the effective management and development of better healthcare services at all levels of the health pyramid. Furthermore, healthcare information are typically used for diagnosis, treatment, education, research, billing and insurance, health system planning, program evaluation, policy formulation, public health education as well as public health monitoring. Hence, healthcare information improves the efficiency of healthcare systems, it enhances the quality of healthcare services and it also improves patients' satisfaction. Consequently, healthcare information must be meaningful, reliable, accurate, timely, complete and valid [1]. Healthcare information are usually found in consultation notes, case notes, hospital admission records, discharge summaries, test results, X-rays, photographs and image slides such as those generated by
Magnetic Resonance Imaging (MRI) and the Computerized Tomography (CT) scanners.

Healthcare information is usually stored in paper files, physical files and in digital or electronic formats. However irrespective of the mode of storage, healthcare information need to be exchanged amongst diverse healthcare providers such as physicians, nurses, pharmacists and laboratory technologists within or across healthcare institutions for effective healthcare delivery. This is because the information created by a healthcare provider can be used by another for decision making irrespective of their geographical locations. For instance, a physician can order for an imaging procedure of a patient in a radiology center. The radiologist takes the picture and sends the image back to the physician who uses the image for decision making.

The flow of information amongst diverse healthcare practitioners can either be in non-electronic format or electronic format. The flow of information in non-electronic formats involves the exchange of information amongst healthcare practitioners in paper based forms while the flow of information in electronic formats involves the use of Information and Communication Technology (ICT) tools to exchange information. Nevertheless, the flow or exchange of information within a Health Information System is plagued with several challenges especially in developing countries such as Nigeria. This is because data collection is majorly manual. Furthermore, there is significant fragmentation and duplication in data collection and storage. Hence, healthcare organizations find it difficult to effectively manage information as it flows within or across the continuum of care. Therefore, the information exchanged is usually untimely. Consequently, this results in inappropriate decision making and care management, inapt research, inappropriate quality assessment, ineffective planning, increase in medical errors and cost as well as a decline in the quality of patients' care. In view of this, this paper examines how information flows within and across healthcare institutions. The paper highlights the shortcomings of information flow in Nigeria healthcare organizations; the paper also appraises the strategies for managing information flow within and across diverse health information systems in Nigeria.

\section{DISTINCTION AMONG DATA, INFORMATION AND KNOWLEDGE IN HEALTHCARE}

In a general sense, the terms data, information and knowledge are interrelated. Data refers to raw facts which consist of symbols that represent objects and events as well as their properties. Information on the other hand refers to organized and structured data which have been processed and can be 
used for decision making. Hence, information is data that have been made useful and relevant for a specific purpose. There is no clear, dominant definition of knowledge. Knowledge, however, can be described as information, description or skills that are acquired through education or experience. There are two basic categories of knowledge. These include tacit knowledge and explicit knowledge. Tacit knowledge according to Sternberg et al. [2] is a form of knowledge that is majorly acquired through experience. Explicit knowledge on the other hand refers to codified knowledge which is usually transmitted in a formal and systematic language [3]. Hence, the terms data, information and knowledge describe overlapping concepts as depicted in Figure 1.

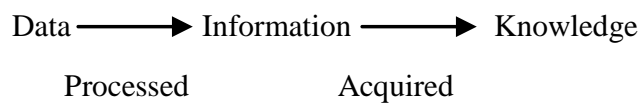

Fig 1: Relationship amongst Data, Information and Knowledge

Nonetheless, the major difference amongst them is in their levels of abstraction, which is as described in Figure 2. Data has the lowest level of abstraction; information is the next level, while knowledge is the highest level of abstraction.

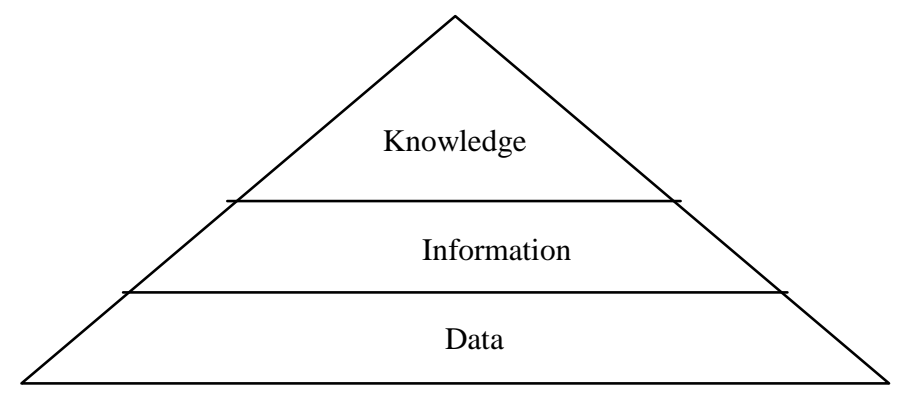

Fig 2: Levels of Abstraction amongst Data, Information and Knowledge

The healthcare system is increasingly a data intensive domain. Hence, the data created and used in this domain must be accurate, comprehensive, accessible, consistent, up-to-date, relevant, timely and it should be well defined so that it can be successfully transformed into meaningful information [4]. Hence, poor data quality increases healthcare costs, hinders health information exchange and healthcare research as well as threatens patient safety [5]. Thus, health information can be regarded as the foundation for better health, the glue holding the health system together and the oil keeping the health system running [6]. According to Wickramasinghe et al. [7], knowledge in healthcare is defined as the capacity to act competently. Hence healthcare practitioners (such as nurses, community health workers, medical doctors, pharmacists) and healthcare policy makers utilize knowledge to improve the health and the well being of individuals as well as their communities. Hence, data has to be analyzed and evaluated to form knowledge that can be used to inform and aid decisionmaking [8]. Consequently, the success of a healthcare system typically relies on how effectively and intelligently knowledge is being used to improve the healthcare process [9].

The healthcare domain involves a wide range of techniques for collecting data/information. These techniques include the following:

\subsection{Census}

According to [10], census can be defined as the enumeration of a population, in addition to the information about members of a household, their sources of income as well as matters relating to their healthcare. Census provides basic information for healthcare systems such as the numbers of births and deaths, causes of death as well as the number of inpatients and outpatients in a particular clinic. Census usually takes place once in every ten years.

\subsection{Physical Examination}

Physical examination is also referred to as clinical examination. It typically involves the investigation or evaluation of a patient's body system for signs and symptoms of diseases. Physical examination also involves taking an individual's vital signs such as temperature, blood pressure and the level of sugar in the body. In addition, physical examination involves the taking of the medical history and life style of the patients, which eventually becomes a part of the patient's medical record.

\subsection{Imaging Techniques}

Data is usually obtained in healthcare via imaging techniques with the use of imaging technologies such as X-rays, magnetic resonance imaging, ultra-sound and digital endoscopy which creates visual representations of a body for medical analysis and intervention.

\subsection{Billing and Insurance}

This provides data on interactions with healthcare systems, inpatients stays, procedures, visits as well as the costs associated with them.

\subsection{Laboratory/Procedures}

Data usually obtained from laboratories include results from blood test and urine tests.

\subsection{Treatment/Therapy}

Data obtained from treatment/therapy include drug name or code, dosage, route of administration, prescription as well as surgical intervention such as organ transplant.

\subsection{Patients' Interviews}

Data obtained from patient interviews include demographics such as date of birth, gender, ethnicity, social security number, contact information, family members, as well as medical history. However, the data obtained via patients' interviews is usually subjective and its usability depends largely on the ability of healthcare practitioners to ask accurate questions and interpret the answers correctly.

\subsection{Household Surveys}

These provide data on individual beliefs, behaviors and practices that are crucial determinants of healthcare use and of health status [11].

\section{THE NIGERIA HEALTHCARE SYSTEM}

The primary objective of the Nigeria healthcare system is to improve the quality, efficiency and effectiveness of healthcare services in Nigeria. The Nigeria healthcare system is provided and maintained by the Federal, State and Local governments, the private sector, as well as religious and non-governmental organizations. The Federal government provides technical support, international relations on health matters, as well as 
healthcare services to tertiary healthcare system such as the Federal Universities teaching hospitals and the Federal Medical Centers (FMCs). The State government is responsible for secondary healthcare which typically comprises the general hospitals and the state owned University teaching hospitals. The state government provides technical support for secondary healthcare [12]. In addition, the Local government is responsible for primary healthcare which is organized through the wards, health districts and health centers [13]. The primary health centers are usually the first point of contact of patients. Furthermore, Iroju [12] emphasized that the private sector provides a larger percentage of healthcare services due to poor coordination and funding of the healthcare system by the three tiers of government. Hence, $75 \%$ of the 3275 secondary health facilities in Nigeria are privately owned [14].

Information flows within the Nigeria healthcare system through interactions amongst healthcare providers and patients in the wards, clinics, pharmacies as well as laboratories. However, information flows across the tiers of the Nigeria healthcare systems by means of the referral system which is as shown in Figure 3. The referral system is a process by which a health worker transfers the responsibility of care temporarily or permanently to another health professional or social worker or to the community [15]. According to Akande [15], the primary healthcare is supposed to be the first point of contact where patients are then referred to other levels of healthcare. The referral process is however usually manual, weak and uncoordinated. Consequently, there is data/information mismanagement in Nigeria healthcare system. Hence, knowledge management as well as access to health information is limited. Consequently, data flow is fragmented in vertical silos thereby creating inefficiencies, duplication of efforts, knowledge gap as well as poor evidence based decision making [14].

Refers

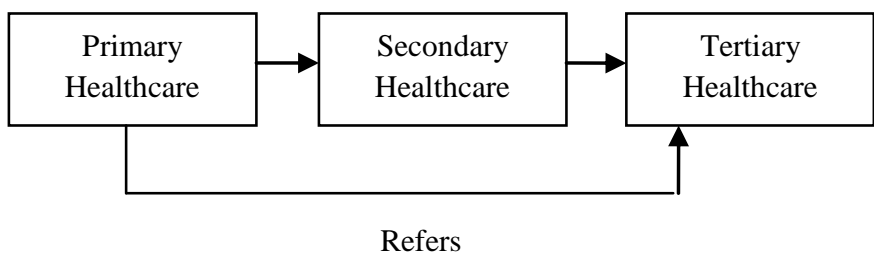

Fig 3: Referral Process in the Nigeria Healthcare System

\section{HEALTHCARE SYSTEMS}

The term information flow describes the transmission of information from one place to another. Information flow also refers to the progressive movement of information through a sequence of processes. In healthcare, the term generally denotes the flow of information along the pathway of care. Information flow typically deals with how care is provided, where care is provided and who provides the care.
Information flow according to The Health Foundation [16] refers to how services are accessed, when and where assessment and treatment is available, and who provides care.

\subsection{Information Flow in Nigeria Healthcare System}

When a patient visits a healthcare system in Nigeria, the first point of contact is usually with a receptionist or an administrative staff who directs the patient to pay for a hospital card. Once the payment is made, a Medical Record Officer (MRO) attends to the patient by issuing the patient a hospital card and assigning the patient a Hospital ID. The MRO gets the patient's demographic data such as name, address, sex and records it in the card. The next point of contact is with a nurse who takes the patient's vital signs and records it in the card. The nurse then directs the patient to a medical doctor who takes information from the patient regarding his ailment and records it in a case note taking into cognizance the patient's hospital id. The doctor diagnoses the patients by performing Physical Examination (PE) and recording his findings in the case note and the card. The doctor may request for a laboratory examination or/and an imaging procedure based on his findings. The laboratory technologist takes blood, urine or other sample of the patient and performs test on it while a radiologist takes the image of the patient. The medical doctor interprets the laboratory or radiologist's results; and either admits, treats or refers the patient based on these results. During the process of treatment, the doctor prescribes drugs to the patient which the patient gets from a pharmacist. Patients on admission will eventually be discharged if well while those that do not get well are referred to the next level of care. An activity diagram which depicts this process is illustrated in Figure 4.

\section{CHALLENGES OF INFORMATION FLOW IN NIGERIA HEALTHCARE SYSTEM}

This section appraises the challenges faced during information flow in Nigeria Healthcare System.

\subsection{Information Exchange is usually Paper Based}

In Nigeria healthcare system, data is usually collected, processed, and stored in paper-based systems, legacy systems and proprietary systems that are heterogeneously developed. Hence, effective communication/ information exchange amongst healthcare practitioners within and across healthcare organizations is poor. This however adversely affects patients care as the timely access to patient's information is hindered. Hence, avoidable deaths and injuries usually occur as a result of poor communication amongst healthcare practitioners [17]. Furthermore, as patients' information grows exponentially over the years, they are usually destroyed by healthcare practitioners due to lack of physical space. 
Patient pays to cashier and takes receipt to
MRO issues patient a card and assigns a

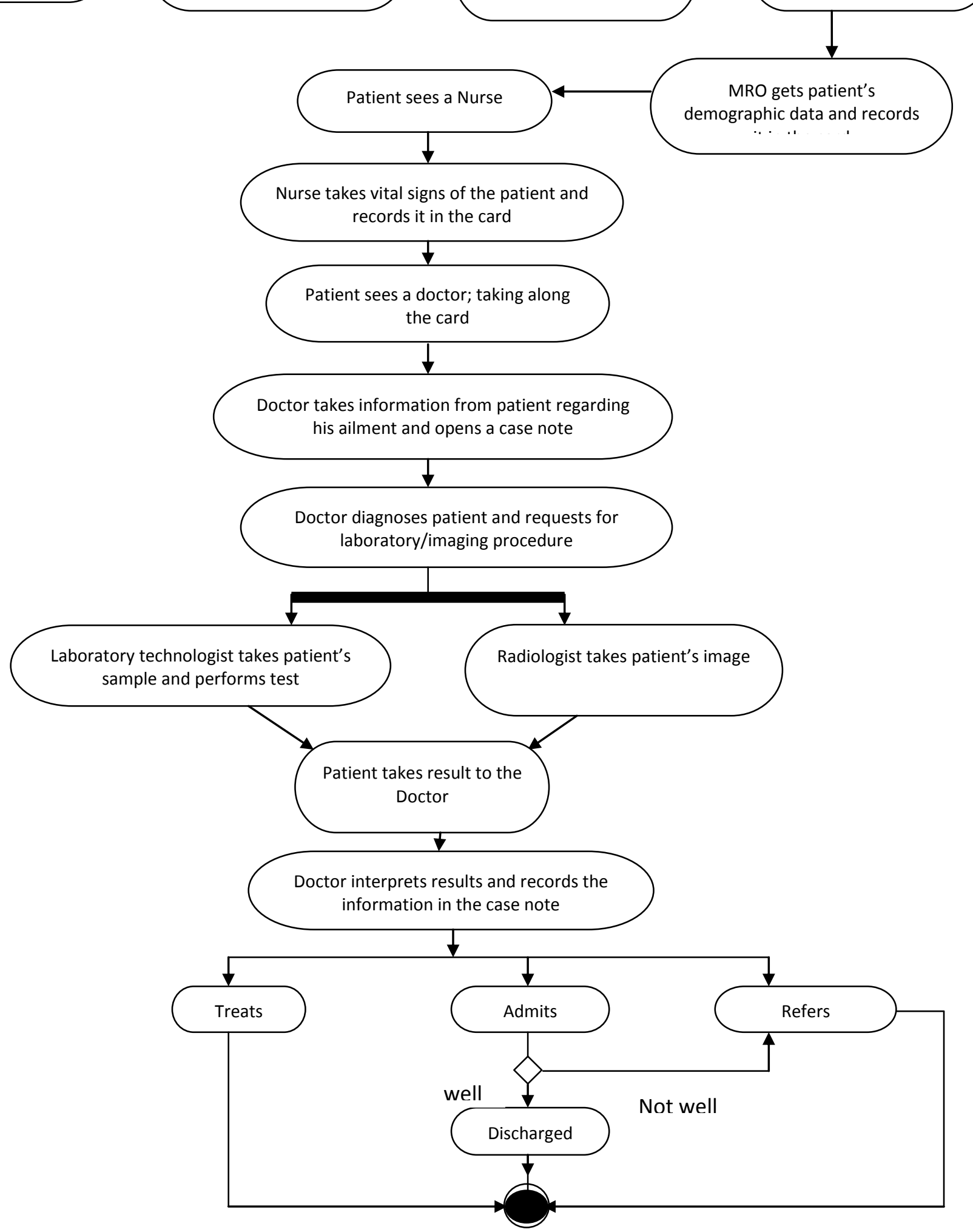

Fig 4: Information Flow in Nigeria Healthcare System 


\subsection{Untimely Delivery of Patients' Information}

Patients' information is not usually delivered promptly to healthcare practitioners at the point of care. Hence, healthcare practitioners do not have immediate and timely access to patients' information. Moreover, information is usually delivered manually to the care providers by the patients. For instance, a patient is usually expected to take the result of a laboratory test to the healthcare practitioner that requests for it. This process is usually manual and time consuming. For instance, the high cost of transportation in areas like the core riverine areas in the Niger Delta may hinder the movement of the patients. Consequently, decisions concerning patients' healthcare are delayed. This in turns affects the patient's care adversely.

\subsection{Lack of Interoperability}

The healthcare system is very complex as it requires the collaborative efforts of diverse healthcare providers during care. Furthermore, patients receive care from more than one healthcare institution. However, patients' information is essentially stored in diverse silos of paper based systems across different healthcare organizations in the Nigerian context. Moreover, healthcare organizations are not also integrated. Consequently, this has led to significant fragmentation and duplication of patients' information and thus impedes the ability of diverse healthcare practitioners to share data. Thus, a practitioner may repeat a medical procedure since he does not have prior information about the patient. Hence, it is difficult to establish a relationship amongst all entities of care in the Nigeria healthcare system. Consequently, healthcare providers are usually presented with incomplete and inconsistent information during care.

\subsection{Poor or no Feedback Mechanism}

There is usually poor or no feedback amongst healthcare providers when patients are referred from one healthcare institution to another. The care of a patient usually ends in a particular healthcare institution as soon as the patient is referred to another point of care. This is because there is no follow up on a patient immediately after referral. Moreover, there is poor integration of private health facilities in the Nigeria's healthcare delivery system [18]. Hence, there is usually no continuity in the flow of information amongst diverse points of care usually from private health institutions and government owned healthcare institutions.

\subsection{Medical Errors}

Patients usually receive care from more than one healthcare provider who can be located in diverse geographical locations. Hence, patients' information are usually scattered in diverse healthcare institutions. This process is however associated with medical errors as a result of inadequate availability of patients information and broken healthcare processes. Hence, the World Health Organization [19] ranked Nigeria 187 of 191 of member states.

\subsection{Rising Cost of Healthcare}

One of the major challenges of Nigeria healthcare system is the rising cost of healthcare. The ineffective communication of data, information and knowledge amongst the stakeholders in the circle of care is a major factor that leads to the increased cost of healthcare in Nigeria.

\subsection{Reduced Quality of Care}

High quality healthcare is usually achieved when there is a relationship as well as effective communication amongst the care providers involved in a patient's care. In addition, healthcare providers must take into consideration patients' satisfaction. However, the ineffective flow of information amongst diverse points of care results in reduced quality of healthcare services in Nigeria.

\section{HOW TO MANAGE INFORMATION FLOW IN NIGERIA HEALTHCARE SYSTEM}

The following section appraises the strategies for managing information flow in the context of Nigeria healthcare system.

\subsection{Introduction of Electronic Health Systems in all tiers of Nigeria Healthcare Delivery System}

Information recording and flow in Nigeria healthcare system are usually paper based in Nigeria healthcare system. Hence, the healthcare system is fragmented and healthcare activities are significantly duplicated. Consequently, there is poor coordination between the primary, secondary and tertiary levels of healthcare. However, if electronic healthcare systems such as the use of mobile technologies, Electronic Health Records as well as Electronic Medical Records are introduced in all levels of Nigeria healthcare system, interoperability will be facilitated. Thus, the effective and seamless flow of healthcare information amongst the stakeholders of care will be enhanced. The Federal Ministry of Health as well as the legislative arm of government should therefore intensify their efforts in enhancing the health reforms program by incorporating electronic health systems in the Nigeria healthcare delivery system. Furthermore, internet facilities as well as telemedicine devices should be made to penetrate the remote rural areas. This will empower individuals, communities as well as healthcare providers with timely and understandable health-related information. This will in turn lead to significant improvements in health outcomes.

\subsection{Human Capacity Building in Electronic Health}

Healthcare providers should be adequately trained on the use of electronic health systems. Healthcare practitioners should be equipped with the appropriate skills, information and knowledge of how to effectively deploy electronic healthcare systems for efficient healthcare services. Healthcare professionals should also be appropriately trained on the maintenance of e-health applications.

\subsection{Formulation of Health Policies that will support E-Health Innovations \\ The legislative arm of Government should formulate policies that will support e-health innovations such as the use of mobile health and telemedicine in healthcare. In addition, Government at all levels should provide an enabling environment for e-health to thrive.}

\subsection{Provision of Adequate Power Supply}

Electronic healthcare systems require electricity to function. However, there is no adequate power supply in Nigeria. Hence, the implementation of electronic healthcare system for information exchange becomes a challenge. Hence, the Federal Government should work towards the provision of 
adequate power supply for the uninterrupted deployment of electronic healthcare systems

\subsection{Security of Health-Related Information in Electronic Healthcare Systems}

Adequate security measures such as the use of passwords, audit trail systems as well as biometrics should be provided to secure patients' information stored in electronic healthcare systems. This will encourage patients to entrust their information to healthcare providers. It will also facilitate the flow of information amongst healthcare providers because the malicious access to health information will be curbed.

\subsection{Usability of Electronic Healthcare Systems}

The use of electronic healthcare systems with well designed user interfaces should be encouraged in Nigeria healthcare system. The knowledge and system requirements of healthcare practitioners should also be sought during the design of electronic healthcare systems. This will ensure that users' requirements are met during system use. Hence, the implementation of electronic health systems for information exchange will be encouraged.

\subsection{Introduction of a Unified Standard for the Exchange of Electronic Health Information}

The Federal Government of Nigeria should introduce a unified standard for the exchange of electronic information. This is because most electronic healthcare systems are heterogeneous in nature, for instance there are developed using different programming languages, diverse operating systems, tools and procedures. Thus, communication amongst the systems becomes a challenge. However, the use of a unified health information exchange standard will facilitate the exchange of information amongst the users of the electronic healthcare systems.

\subsection{Integration of all Tiers of Healthcare}

The Federal Government of Nigeria should make efforts to integrate all the tiers of healthcare provided by the government with healthcare provided by private and nongovernmental organizations. Hence, the immense involvement of private healthcare organizations will be recognized by the Federal Government. This will facilitate interactions amongst diverse healthcare practitioners as well as the continuous flow of information across the continuum of care.

\section{A COMPARATIVE ANALYSIS OF INFORMATION FLOW IN HEALTHCARE SYSTEMS ACROSS DIVERSE COUNTRIES}

Information flow in healthcare systems varies from country to country. Hence, this section gives a comparative analysis of how information flows in developing countries using Ethiopia as a case study and developed countries using Sweden and the United States of America (USA). In Ethiopia, the collection, compilation, analysis, utilization and flow of health information remains a major problem [20]. In addition, the flow of health information amongst healthcare providers is fragmented. This results in redundant and conflicting reports as well as poor health data quality in terms of completeness, accuracy and timeliness [20]. In Sweden however, the healthcare system has largely dispensed records on paper with the use of Electronic Medical Records (EMRs) [21]. In spite of this innovation, the Sweden healthcare system is suffering from severe interoperability problem [22]. This is as a result of the absence of a common infrastructure that will facilitate the seamless flow of information amongst the users of the EMRs. In the USA, the flow of healthcare information is by the use of paper based system and Information and Communication Technology Systems (ICTs). However the flow of information across diverse healthcare institutions electronically is hindered by the lack of consensus on how to transmit data. This however results in injury, wasted resources and loss of lives. It can therefore be deduced that interoperability is a majorly challenge of most healthcare systems. Table 1 briefly compares the flow of information in Nigeria healthcare system, Ethiopia healthcare system, Sweden healthcare system and the USA healthcare system.

Table 1. A comparative analysis of information flow in Nigeria healthcare system, Ethiopia healthcare system, Sweden healthcare system and the USA healthcare system

\begin{tabular}{|l|l|l|l|}
\hline $\begin{array}{c}\text { Nigeria } \\
\text { Healthcare } \\
\text { system }\end{array}$ & $\begin{array}{c}\text { Ethiopia } \\
\text { healthcare } \\
\text { system }\end{array}$ & \multicolumn{1}{c|}{$\begin{array}{c}\text { Sweden } \\
\text { healthcare } \\
\text { system }\end{array}$} & $\begin{array}{c}\text { USA } \\
\text { healthcare } \\
\text { system }\end{array}$ \\
\hline $\begin{array}{l}\text { Information } \\
\text { flow is } \\
\text { majorly } \\
\text { paper based }\end{array}$ & $\begin{array}{l}\text { Information } \\
\text { flow is } \\
\text { majorly paper } \\
\text { based }\end{array}$ & $\begin{array}{l}\text { Information flow } \\
\text { is largely } \\
\text { electronic }\end{array}$ & $\begin{array}{l}\text { Information } \\
\text { flow is both } \\
\text { paper based } \\
\text { and } \\
\text { electronic }\end{array}$ \\
\hline $\begin{array}{l}\text { Data flow is } \\
\text { fragmented }\end{array}$ & $\begin{array}{l}\text { Data flow is } \\
\text { fragmented }\end{array}$ & $\begin{array}{l}\text { Data flow is } \\
\text { fragmented }\end{array}$ & $\begin{array}{l}\text { Data flow } \\
\text { is } \\
\text { fragmented }\end{array}$ \\
\hline $\begin{array}{l}\text { interoperabil } \\
\text { ity is a major } \\
\text { challenge }\end{array}$ & $\begin{array}{l}\text { interoperabilit } \\
\text { y is a major } \\
\text { challenge }\end{array}$ & $\begin{array}{l}\text { interoperability is } \\
\text { a major challenge }\end{array}$ & $\begin{array}{l}\text { interoperabi } \\
\text { lity is a } \\
\text { major } \\
\text { challenge }\end{array}$ \\
\hline
\end{tabular}

\section{CONCLUSION}

Information is a very vital component of any healthcare system. This is because information is useful for decision making, policy formation, research purposes as well as administrative and clinical purposes. However, most healthcare organizations in Nigeria store information in silos of paper based systems. Consequently, healthcare information is fragmented and broken and thus the flow and exchange of information in Nigeria healthcare becomes a challenge. Consequently, the Nigeria healthcare system is fraught with medical errors, rising cost, lack of interoperability as well as poor feedback mechanism. It is therefore against this backdrop that this paper examines the strategies for managing the flow of information in the context of Nigeria healthcare system. The paper suggests that the deployment of electronic healthcare system, building human capacity in healthcare, provision of policies that facilitate the implementation of ehealth systems, the provision of a unified standard for health information exchange as well as the integration of private healthcare organizations with the Government owned healthcare organizations are some of the strategies for managing information flow within the context of Nigeria healthcare system. Consequently, healthcare providers will have the right information at the right time to provide the appropriate care to their patients. However, for future enhancement, this study will critically examine the challenges of seamless flow of information in healthcare systems in 
different countries across the globe. This study will also propose methods for ensuring seamless flow of information amongst stakeholders in the circle of care.

\section{REFERENCES}

[1] Lungo, J.H. 2003. Data Flows in Health Information Systems. Master's Thesis. Department of Informatics, University Of Oslo.

[2] Sternberg, R. and Horvath, J. 1999. Tacit Knowledge in Professional Practice: Researcher and Practitioner Perspectives. Routledge

[3] Nonaka, I. and Takeuchi, H.. 1995. The Knowledgecreating Company: How Japanese Companies Create the Dynamics of Innovation. Oxford University Press, Oxford.

[4] America Health Information Management Association (AHIMA). 2007. Statement on Quality Healthcare Data and Information. America Health Information Management Association.

[5] America Health Information Management Association (AHIMA) e-HIM Workgroup on EHR Data Content. Data standard time: Data content standardization and the HIM Role. Journal of AHIMA 77. 1 (2006), 26-32.

[6] Lippeveld, T. 2001. Routine Health Information Systems: The Glue of a Unified Health System. Keynote Address at the Workshop on Issues and Innovation in Routine Health Information in Developing Countries, Potomac.

[7] Wickramasinghe, N., Gupta, J.N.D. and Sharma S.K. 2005. Creating knowledge-based Healthcare Organizations. Idea Group Publications, Hershey.

[8] Vital Wave Consulting. 2009. Health Information Systems in Developing Countries. Research Paper and Strategic Briefing. Vital Wave Consulting.

[9] Borda-Rodriguez, A. 2011. Knowledge in Development Aid and Healthcare: A Comparative Analysis. Ikd Working Paper No. 61. Development Policy and Practise,The Open University.

[10] Mosby Medical Dictionary. 2009. Census. Mosby Medical Dictionary.
[11] World Health Organization. 2008. Health Information System.http://www.who.int/countries/moz/areas/health_i nfo_system/en/index.html.

[12] Iroju,O.G. 2014. Capacity Building in Electronic Health in Nigeria Healthcare Delivery System. In Proceedings of $3{ }^{\text {nd }}$ Interdisciplinary International Conference, Nigeria.

[13] Iroju, O., Soriyan, A., Gambo, I., and Olaleke, J. 2013. Interoperability in Healthcare: Benefits, Challenges and Resolutions. International Journal of Innovative and Applied Studies, Morocco, 3(May. 2013), 262-270.

[14] Annan,K. 2002. Executive Summary of Strengthening Health Systems in Nigeria. The Nigerian Academy of Science, Lagos, Nigeria.

[15] Akande, T.M. 2004. Referral System in Nigeria: Study of a Tertiary Health Facility. Annals of African Medicine 3(2004), $130-133$.

[16] The Health Foundation. 2013. Improving Patient Flow. The Health Foundation Inspiring Improvement.

[17] Iroju,O., Gambo,I., Ikono, R. and Olaleke, J.O. Interoperability in Nigeria Healthcare: The Ways Forward. International Journal of Information Engineering and Electronic Business. 4 (Oct. 2013), 1623.

[18] Mohammed, D. 2002. National Health Insurance Scheme: Towards Universal Coverage By 2020. The Nigerian Academy of Science, Lagos, Nigeria.

[19] Ayodele, C.B. 2011. Hospital Information Systems in Nigeria: A Review Of Literature. Journal of Global Healthcare Systems, 2011, 1(2011), 1-26.

[20] Ayeta, M. 2013. Assessment of Health Management Information System (HMIS) Performance at Health Facilities of Afar Region. Amref Health Africa International Conference, Nairobi, Kenya.

[21] Leonard, D. and Tozzi, J. 2012. Why Don't More Hospitals Use Electronic Health Records?.Bloomberg Business week

[22] Folster, S., Hallström O., Morin A. and Renstig M. 2003. Den Sjuka Vården. Stockholm, Ekerlids. 